\title{
O TEMPO DOS VERBOS COMO CATEGORIA DE ANÁLISE TEXTUAL
}

\section{THE VERBAL TENSE AS A CATEGORY OF TEXTUAL ANALYSIS}

\author{
Alena Ciulla \\ Universidade Federal do Rio Grande do Sul, UFRGS, Porto Alegre, RS, Brasil
}

Resumo: O tempo verbal, tradicionalmente classificado em presente, pretérito e futuro, revestese de uma importância capital sob a perspectiva benvenisteana, que salienta o seu papel fundamental na linguagem, na alternância entre dois diferentes planos de enunciação. Com base na proposta do autor de, entáo, distinguir os tempos dos verbos, de acordo com a relaçáo que estabelecem com a instância do discurso de quem fala, apresentamos, neste trabalho, uma abordagem inicial de análise do sistema de tempos verbais do português, investigando como os planos de enunciaçáo podem estar associados a diferentes modos de conduzir o processus textual.

Palavras-chave: Modos enunciativos; Processus textual; Sistema verbal do Francês; Sistema verbal do português; Tempo verbal.

Abstract: The verbal tense, traditionally classified as present, past and future, assumes paramount importance from Benveniste's perspective, which highlights its fundamental role in language, in the alternation between two different enunciation plans. Based on the author's proposal, in order to distinguish verbal tenses according to their relationship with the instance of discourse, we present an initial approach of the Portuguese verbal system, investigating how the enunciation plans can be associated to different ways of conducting the textual processus.

Keywords: Enunciation plans; French verbal system; Portuguese verbal system; Textual Processus; Verbal tense.

\section{Introdução}

Ainda que haja uma grande produção de trabalhos sobre os verbos, tais estudos circunscrevem-se, de modo geral, ao domínio gramatical. Além disso, mesmo em estudos de aspectos mais semânticos sobre o verbo, a maior parte conserva as tradicionais classificaçóes do verbo em tempo, modo e aspecto, desprezando a questão fundamental da atuação dos verbos 
no processus dos enunciados, conforme apontou, pioneiramente, Benveniste (1966) e será destacado neste trabalho.

Iniciamos esta discussão, buscando compreender como Benveniste (1966) relaciona os tempos verbais com a distinçáo entre os planos enunciativos histórico e discursivo. A partir dessa reflexão, que envolve compreender também como os verbos estabelecem um vínculo com a instância do discurso do locutor, reunimos alguns elementos para um estudo do sistema verbal do português. É em Benveniste (1966) mesmo que encontramos respaldo para essa aposta. Explicamos: para sugerir os planos de enunciação, entre o histórico e o discursivo, com base nos tempos verbais, o autor parte do sistema de verbos do francês, mas dá indicaçôes de que é possível analisar o sistema verbal de outras línguas sob a mesma ótica, ao observar, por exemplo, sobre a questáo da importância do aoristo para o plano histórico:

Entre os textos que serviriam de testemunha, devemos incluir também as traduçôes, que nos apontam para as equivalências espontâneas que um autor encontra para fazer passar uma narrativa escrita para uma outra língua no sistema temporal que convém ao francês. (BENVENISTE, 1966, p. 244)

Há pelo menos duas questôes que extraímos daqui. Primeiramente, que é interessante verificar, em outras línguas, como o aparato verbal se organiza para distinguir os diferentes modos enunciativos. Uma segunda questão é o fato de que a tradução pode ser um ponto de vista do estudo das línguas, conforme já indicou também Hoff (2018).

Além disso, Benveniste (1966) fornece fundamentos - e chega mesmo a identificar alguns gêneros de texto - que possibilitam propor a marca temporal dos verbos e suas relaçóes com os diferentes planos de enunciação como importante subsídio para a análise de textos. No que diz respeito à análise de textos, encontramos inspiração também em Weinrich (1973), que aprofunda e desenvolve a teoria benvenisteana, alimentando nossa proposta com dois conceitos: um sobre a persistência de tempos verbais em um texto, o que ele chama de "obstinação", e outro sobre características dos dois planos enunciativos, os quais ele designa como dois diferentes "mundos".

Partindo, então, desses trabalhos, formulamos a hipótese de que o estudo dos sistemas verbais pode ser profícuo, ajudando a compreender o emprego dos tempos verbais nas diferentes línguas e associando-os aos planos de enunciação. Tais planos de enunciação podem, por sua vez, estar relacionados a diferentes modos de conduzir o processus textual. Essas 
possibilidades de análise serão exploradas em dois textos em português.

Nosso intuito neste trabalho é o de desenvolver a reflexão em dois aspectos, o primeiro, mais específico, o segundo, mais geral: 1) compreender melhor as dimensóes dos dois planos de enunciação e fazer uma primeira abordagem sobre o comportamento dos verbos do português em relação a esses diferentes modos enunciativos, partindo de uma comparação com os achados de Benveniste (1966) e de Weinrich $(1964 ; 1973)$ para o francês e para o alemão e 2) apontar para a possibilidade de tratar o tempo como categoria de organização textual.

\section{As relaçóes do tempo no verbo francês e possibilidades de prospecçáo}

Em As relaçôes do tempo no verbo francês, de 1959, Benveniste (1966) problematiza o sistema de verbos do francês, primeiramente contestando as divisóes gramaticais do tempo em presente, passado e futuro. Para o autor, esse paradigma temporal não corresponde à realidade de emprego e não esclarece muito sobre como os verbos podem ser organizados. Por exemplo, questiona Benveniste, qual classificação temporal poderia dar suporte, para que se aceite ou rejeite o paradigma de sortir em uma expressão como il allait sortir? Ou, e aqui invertemos a questáo, por que, em detrimento da forma sortir, é allait, nessa expressão, que determina o tempo verbal da ação? No caso da tradicional oposiçáo entre formas simples e compostas dos verbos do francês também o critério escapa a uma observação rigorosa:

Se há a necessidade de opor il courait e il avait couru, não é, em todo o caso, sobre o mesmo eixo de tempo em que il courait se opóe a il court. E, no entanto, il a couru é certamente, de alguma maneira, uma forma temporal, pois pode ser equivalente a il courut. Mas il a couru serve ao mesmo tempo de parceiro de il court. (BENVENISTE, 1966, p. 237) ${ }^{1}$

Como se vê, as relaçóes entre as formas, compostas e simples, e o tempo sáo ambíguas numa abordagem mais superficial. De acordo com Benveniste (1966), mesmo a explicação tradicional da gramática sobre o aspecto, que poderia ser levada em conta nesses casos, náo se configura como um princípio unívoco de correlação entre uma forma e outra e, além disso, permanece a questáo de por que algumas formas compostas são efetivamente

\footnotetext{
${ }^{1}$ A tradução desse trecho, bem como de todos os outros, de obras citadas, que foram consultadas nas suas ediçóes nas línguas originais, é de responsabilidade da autora deste artigo.
} 
consideradas como temporais e outras não. A questão inicial do autor, nesse texto de 1959, é, então, sobre quais formas devem ser consideradas como temporais.

E é a partir do que poderia parecer uma "falha" do sistema, que Benveniste encontra uma primeira pista para explicar melhor a natureza das relaçôes do verbo: a expressão temporal do passado é redundante, em francês, e dispóe de duas formas, quais sejam, o passado simples e o passado composto. Por exemplo, para o verbo faire, conjugado na terceira pessoa, as formas são il fit e il a fait, respectivamente. Na interpretação tradicional, seriam duas variantes da mesma forma, entre as quais se escolhe, de acordo com uma situaçáo de escrita (il fit) ou de fala (il a fait). Conforme uma explicação diacrônica, teríamos, nesse caso, uma fase de transição, em que a forma arcaica il fit se manteria na língua escrita, que costuma ser mais conservadora, enquanto que a língua falada, mais dinâmica, avançaria para a forma substituta il a fait. Sem assumir a redução desse fenômeno a uma questáo de sucessão, contudo, Benveniste (1966) convida à reflexão, em primeiro lugar, questionando sobre o motivo pelo qual a língua escrita e a falada teriam se divorciado no que diz respeito à temporalidade, e não em relação a outras questôes. Além disso, questiona também por que esse mesmo divórcio náo se aplica a outras formas paralelas, como, por exemplo, il fera e il aura fait, que permanecem distintas.

Para Benveniste, a distinção do emprego de il fit e il a fait tem uma outra motivação, que não é exatamente pela alternância entre a escrita e a fala, e muito menos por uma questão de sucessão diacrônica. O tempo de il fit é o aoristo, ou passado simples, que além de caracterizar a narrativa de eventos no passado, também tem um efeito de objetividade, isto é, os acontecimentos expressos nessa forma verbal são tratados como se tivessem sido produzidos sem qualquer intervenção do locutor. Com isso, a forma do aoristo assinala a intenção histórica, imprimindo a temporalidade específica para os eventos do passado que se quer relatar como objetivos e excluindo as pessoas (eu e tu) da narrativa. Já il a fait, cuja forma temporal é a do passado composto, tem um emprego diferente, pois ainda que expresse também um acontecimento no passado, implica a referência ao tempo presente de quem enuncia. Trata-se, neste último caso, não mais de um passado histórico e objetivo, mas de um passado, em que o locutor é testemunha. Para o autor, entáo, é preciso reexaminar a estrutura do verbo por inteiro, sendo que uma descrição das relaçóes de tempo constitui a tarefa mais necessária. E acrescenta: 
Os paradigmas das gramáticas levam a crer que todas as formas verbais tiradas de um mesmo tema pertencem todas à mesma conjugação, em virtude unicamente da morfologia. Entretanto, nos propomos mostrar aqui que a organização dos tempos depende de princípios menos evidentes e mais complexos. Os tempos de um verbo francês não se empregam como os membros de um sistema único, distribuem-se em dois sistemas complementares. Cada um deles compreende apenas uma parte dos tempos do verbo; todos os dois estáo em uso concorrente e permanecem disponíveis para cada locutor. Esses dois planos manifestam dois planos de enunciação diferentes. (BENVENISTE, 1966, p. 237)

A importância dessa observação de Benveniste é melhor compreendida, levando-se em conta a distinção que o autor faz, entre pessoa e náo pessoa, e a fundamental relaçáo que se estabelece nos enunciados, a partir dessa distinção. Isso porque são justamente as funçóes desempenhadas por eul tu de um lado, e por ele/nomes lexicais de outro, associando-se também aos tempos verbais, como estamos defendendo aqui, que revelam esses dois planos de enunciação a que se refere Benveniste.

Por isso, sobre a distinção da categoria de pessoa (que aparece, em especial, no texto Estrutura das relaçôes de pessoa no verbo, de 1946) relembramos alguns pontos, em especial a constataçáo fundamental de que apenas eu e $t u$ são as verdadeiras pessoas, pois sáo os únicos que participam do ato enunciativo, ao passo que ao pronome ele e aos nomes lexicais fica reservado o papel de não pessoa, referindo somente um predicado, que é enunciado sempre fora da relaçáo $e u$ - $t u$. Conforme já assinalamos em trabalho anterior:

O ponto a ressaltar é o de que, quando alguém toma a palavra e enuncia "eu", estabelece um $t u$, compulsoriamente, a quem se dirige. Assim, essas duas pessoas são sempre implicadas no que é dito. Por outro lado, ele será sempre o ausente da relaçáo $e u$-tu e, por isso, o seu enunciado será somente um predicado não imputável a eu. (CIULLA, 2020a, no prelo)

É assim, aqui de maneira bastante resumida, que são identificados por Benveniste (1966) dois modos de linguagem, um em que atuam as remissóes de pessoa, que não refere coisas, mas somente a própria instância de discurso de $e u$, e outro, em que atua a não pessoa, responsável pela referência a toda e qualquer coisa. Por remeter a coisas do mundo, cuja representação tem base no léxico, categoria (relativamente) estável das línguas, é atribuída à náo pessoa um caráter de objetividade. Já eu e tu são elementos da ordem da subjetividade, pois se circunscrevem à instância de discurso que os contém e 
variam, portanto, a cada vez que um locutor toma a palavra.

Isso posto, podemos compreender como Benveniste (1966) distingue os tempos dos verbos, de acordo com a sua solidariedade à instância do discurso de quem fala: a marca de pessoa embutida no tempo verbal, ou a sua ausência, comanda os diferentes modos de linguagem em que o autor situa os planos discursivo e histórico, respectivamente.

\section{A distribuiçáo dos tempos verbais entre os planos discursivo e histórico}

A enunciação histórica está situada no domínio do objetivo, ou seja, quando o verbo no passado reflete uma relação cronológica de anterioridade no próprio enunciado, que, assim, se apresenta na "realidade objetiva". Pertencem ao plano histórico, tipicamente, aquilo que se conta de acontecimentos passados, como acontece em livros de história, em que não aparecem análises explícitas de historiadores, mas apenas o relato impessoal, dos fatos que se produziram em um passado desatrelado do presente de quem os narra. Por isso, são excluídas desse plano, de acordo com Benveniste (1966), todas as formas linguísticas autobiográficas. Para o autor, a intenção histórica constitui uma das grandes funçôes da língua, imprimindo-lhe uma temporalidade específica, cujas marcas formais devemos observar.

O historiador nunca dirá $e u$ nem $t u$, nem aqui, nem agora, porque ele nunca requisitará o aparelho formal do discurso, que consiste sobretudo na relação de pessoa eu:tu. Constataremos, portanto, na narrativa histórica estritamente processada, somente formas de $3^{a}$ pessoa. (BENVENISTE, 1966, p. 239)

São as formas de $3^{\text {a }}$. pessoa (ou não pessoa) que definem a expressão do campo temporal da enunciação histórica. Para o francês, os tempos que a comportam, conforme Benveniste (1966), são principalmente três: o aoristo, o imperfeito (incluindo o condicional) e o mais que perfeito. Todos eles são pretéritos: para serem considerados como dados, precisam pertencer ao passado.

Os exemplos do autor para esclarecer a "ossatura histórica" do verbo francês são, além de trechos de um livro de história grega, o de um romance de Balzac. A diferença deste último, é que os fatos são ficcionais, mas se mantém, em relação ao livro de história grega, o intuito de afastar tudo que é estranho ao estrito relato dos acontecimentos, como opinióes, comparaçóes e quaisquer comentários pessoais. Benveniste (1966, p.240) observa, em 
nota, que a enunciação histórica dos acontecimentos é independente da sua verdade "objetiva", pois o que analisamos aqui é o propósito "histórico" de quem enuncia.

A seguir um dos trechos do livro de história apresentado por Benveniste (1966, p. 240). Os verbos estão grifados em itálico pelo próprio autor.

Pour devenir les maîtres du marché méditerranéen, les Grecs déployèrent une audace et une persévérance incomparables. Depuis la disparition des marines minoenne et mycénienne, l'Égée était infestée par des bandes de pirates : il n'y eut longtemps que des Sidoniens pour oser s'y aventurer. Les Grecs finirent pourtant par se débarrasser de cette plaie : ils donnèrent la chasse aux écumeurs de rivages, qui durent transférer le principal thép̂tre de leurs exploits dans l'Adriatique. Quant aux Phéniciens qui avaient fait profiter les Grecs de leur expérience et leur avaient appris l'utilité commerciale de l'écriture, ils furent évincés des côtes de l'Ionie et chassés des pêcheries de pourpre égéennes; ils trouvèrent des concurrents à Cypre et jusque dans leurs propres villes. Ils portèrent alors leurs regards vers l'Ouest; mais là encore les Grecs, bientôt installés en Sicile, séparèrent de la métropole orientale les colonies phéniciennes d'Espagne et d'Afrique. Entre l'Aryen et le Sémite, la lutte commerciale ne devait cesser $^{2}$ dans les mers du Couchant qu'à la chute de Carthage.

$$
\text { (G. GLoTz, Histoire grecque, 1925, p. 225.) }
$$

E o trecho do romance de Balzac, também em Benveniste (1966, p. 241): 
Après un tour de galerie, le jeune homme regarda tour à tour le ciel et sa montre, fit un geste d'impatience, entra dans un bureau de tabac, y alluma un cigare, se posa devant une glace, et jeta un regard sur son costume, un peu plus riche que ne le permettent ${ }^{1}$ en France les lois du goût. Il rajusta son col et son gilet de velours noir sur lequel se croisait plusieurs fois une de ces grosses chaînes d'or fabriquées à Gênes; puis, après avoir jeté par un seul mouvement sur son épaule gauche son manteau doublé de velours en le drapant avec élégance, il reprit sa promenade sans se laisser distraire par les oillades bourgeoises qu'il recevait. Quand les boutiques commencèrent à s'illuminer et que la nuit lui parut assez noire, il se dirigea vers la place du Palais-Royal en homme qui craignait d'être reconnu, car il côtoya la place jusqu'à la fontaine, pour gagner à l'abri des fiacres l'entrée de la rue Froidmanteau...

\section{(BaLzAc, Études philosophiques : Gambara.)}

Benveniste (1966) observa, sobre os dois excertos, que se mantém a relação temporal constante do aoristo, do imperfeito e do mais que perfeito, conforme se pode ver pelas formas verbais salientadas em itálico. E acrescenta:

Os acontecimentos são colocados como se fossem produzidos na medida em que aparecessem no horizonte da história. Ninguém fala aqui; os acontecimentos parecem se contar por si próprios. O tempo fundamental é o aoristo, que é o tempo de acontecimento fora da pessoa de um narrador. (BENVENISTE, 1966, p. 241)

A forma do aoristo é bastante peculiar. Talvez para um falante de uma língua que não apresenta esse tempo, como o português, seja difícil de imaginar, pois trata-se de um passado que não se constitui como tal em relação ao presente, que, como sabemos, é sempre o presente de quem fala. O aoristo se caracteriza como uma forma temporal "absoluta" do passado, sem relação com o presente de quem enuncia, e é empregada para representar um fato momentâneo e isolado, em um passado determinado não subjetivamente, portanto, mas historicamente.

Um outro exemplo de uso do aoristo, que acrescenta um traço não explorado nos exemplos de Benveniste (1966), é o que encontramos em uma interpretação da tradução da Bíblia, em um blog intitulado La traduction du 
monde nouveau. Sincère? (2008), do seguinte versículo, atribuído a Joāo:

Jean 3:6 Quiconque demeure en union avec lui ne pratique pas le péché; quiconque pratique le péché ne le vit pas et ne pas non plus parvint à le connaître. (La traduction du monde nouveau. Sincère?, 2008)

Neste versículo, conforme a explicação encontrada no blog, João teria utilizado o aoristo ${ }^{2}$ (ne le vit pas - ne pas non plus parvint) para falar de alguém que teria cometido um pecado isolado, o que pode acontecer com qualquer um de nós em algum momento, em razão de nossa imperfeição. Assim, um cristáo, em um momento dado, no passado, pode cometer um pecado, conforme o blog, sem que isso o faça continuar pecando no momento presente: este ensinamento teria sido a motivação de Joáo para o emprego do aoristo. Outra possibilidade de expressão do aoristo nesses casos bíblicos, aponta o blog, é o de uma exortação ou advertência, para que náo se faça uma coisa que ainda não se começou a fazer - como se, com essa forma verbal, tal ação pecaminosa ficasse presa em um tempo distante, sem relação com a ação atual dos cristãos no presente, que estariam, assim, livre de atos pecaminosos. Nessa interpretação, o aoristo permanece como uma forma do plano histórico, sendo que a ausência da relação com o presente é o que permitiria esse efeito adicional de afastamento do pecado.

Ao plano histórico contrapóe-se um outro plano enunciativo, como já mencionado, que é quando a categoria de pessoa, indissociável do tempo do verbo, é marcada ou está implicada no tempo verbal: instaura-se, então, o modo do discurso, para Benveniste (1966). Esse plano encampa toda e qualquer enunciação que suponha um locutor e um ouvinte, além da marca de um engajamento, ou do convite ao engajamento, partindo do locutor. Por isso, o autor cita como exemplo os gêneros orais de texto, mas estão aí incluídos todos os gêneros em que o locutor organiza sua fala na categoria de pessoa.

No plano do discurso, cabem formas verbais do passado, desde que tenham alguma implicação no tempo atual. É importante observar, ainda, que nesse modo enunciativo são empregadas livremente todas as formas pessoais do verbo, isto é, tanto eu/tu quanto ele. Benveniste (1966) chama a atençáo para o fato de que, mesmo que por vezes mais velada, a relaçáo de pessoa está sempre presente e, por isso, a $3^{\text {a }}$. pessoa não tem o mesmo

²Não há menção, no blog, da língua fonte da traduçâo para o francês, apenas supomos que seja o grego, em parte, pela afirmação de que "João teria utilizado o aoristo". Contudo, para nós, isso não é relevante, mas, sim, o emprego que se faz do aoristo em francês nesse caso. 
valor no plano discursivo e no plano histórico. Na narrativa histórica, como o narrador não intervém, a $3^{\text {a }}$. pessoa não se contrapóe a nenhuma outra: há, conforme Benveniste (1966, p. 243) "uma ausência de pessoa". No plano discursivo há uma oposição entre eu/tu e ele. Além disso, todos os tempos verbais do francês são possíveis no plano discursivo, com exceção do aoristo, que, como explicamos, pertence sempre ao plano histórico.

No texto de 1959, Benveniste (1966) faz ainda uma análise das relaçôes entre os verbos simples e compostos, as quais implicam também na configuração dos planos de enunciação. Observa o autor que, de modo geral, as relaçóes entre formas simples e compostas náo são temporais. $\mathrm{O}$ fato de que estejam em concorrência il ecrivit e il a écrit não contradiz a afirmação, pois a forma no passé composé, como vimos, não concorre com a forma do aoristo: sob o ponto de vista do modo enunciativo, ela tem função diferente. Os tempos compostos, de acordo com Benveniste (1966), tem um duplo estatuto. Em primeiro lugar, essas formas mantêm uma oposição com as formas simples, por lhes fornecerem um correlato no perfeito ${ }^{3}$. É uma relaçáo de temporalidade, portanto, que se estabelece paradigmaticamente. A segunda característica do duplo estatuto dos tempos compostos, segundo Benveniste (1966), é a função de indicar anterioridade, que é determinada sempre em relação ao tempo simples correlativo. Essa relação é, portanto, intralinguística, não uma relação cronológica da realidade objetiva. Assim, em francês, o exemplo de Benveniste (1966, p.248) é " 'Quand il a fait son travail, 'il part", explicando que "o anterior do presente '(quand) il a fait' se opóe ao presente 'il part' e deve seu valor a esse contraste. É uma relação sintagmática.”.

Uma última observação sobre os tempos compostos que nos interessa, neste trabalho, particularmente, é a de que "os tempos compostos, quer indiquem o 'acabado' ou a anterioridade, tem a mesma repartiçáo que os tempos simples quanto aos dois planos de enunciaçáo. Eles pertencem também, uns ao discurso, outros à narrativa" (BENVENISTE, 1966, p. 247). Todavia, todas essas conclusóes sobre as relaçóes entre tempos simples e compostos, que valem para o francês, não podem ser aplicadas diretamente para o sistema do português, sem que antes se faça um estudo específico para cada língua. O que fica para esta nossa primeira abordagem, em que um estudo detalhado de formas simples e compostas foge ao escopo, é o que

${ }^{3}$ No francês, "chamamos de 'perfeito' a classe inteira das formas compostas (com avoir e être), cuja funçấo - sumariamente definida, mas de maneira suficiente aqui consiste em apresentar a noção como 'acabada' com relação ao momento considerado e à situação 'atual', resultante dessa realização temporalizada." (BENVENISTE, 1966, p. 246) 
Benveniste destaca, a seguir:

$\mathrm{O}$ essencial era o de fazer aparecer essas grandes divisóes, às vezes pouco visíveis, que percorrem o sistema temporal do verbo francês moderno. Algumas delas, como as que distinguem a narrativa histórica e o discurso, criam dois subsistemas de tempo e de pessoas verbais; outra, a do presente e do perfeito, não é da ordem temporal; mas a cada nível temporal, o perfeito comporta duas funções que a sintaxe distingue: a função de ação acabada e a função de anterioridade, simetricamente repartidas, em parte por refacção, entre a narrativa e o discurso. $\mathrm{O}$ quadro de uma conjugaçáo de um verbo francês, em que os paradigmas se alinham, completos e uniformes, não deixa nem mesmo suspeitar que um sistema formal do verbo tem uma estrutura dupla (conjugação do presente e conjugação do perfeito), bem como é dupla essa organização temporal, fundada nas relaçôes e nas oposições que são a realidade da língua. (BENVENISTE, 1966, p. 250)

Para cada língua, então, é preciso verificar como o sistema se estrutura e como as formas verbais se distribuem, para dar conta dessa dupla organização temporal, entre a narrativa e o discurso.

\section{As formas verbais e sua atuaçáo no processus dos textos}

Em Ciulla (2020a) já observamos que, para além da distinção formal de categorias de pessoas e de tempos verbais, Benveniste (1966) aponta para o funcionamento desses elementos nas línguas. Assim, é ultrapassado o nível meramente gramatical e são alcançadas outras relações, que abarcam a amplitude dos textos, a nosso ver, como no caso das relaçôes de pessoa e tempo verbal, em que se distinguem dois planos de enunciação. Notadamente, a seguinte passagem traz indícios que confirmam essas observaçóes:

Entre $e u$ e um nome referente a uma noção lexical, não há somente as diferenças formais, muito variáveis, que a estrutura morfológica e sintática das línguas particulares impooe. Há outras, que se devem ao próprio processus de enunciação linguística e que são de uma natureza mais geral e mais profunda. $\mathrm{O}$ enunciado que contém eu pertence ao nível ou tipo de linguagem que Charles Morris chama de pragmático, que inclui, com os signos, aqueles que os empregam. Podemos imaginar um texto linguístico de grande extensão - um tratado científico, por exemplo - em que eu e tu não apareceriam uma única vez; inversamente, seria difícil conceber um curto texto falado em que náo fossem empregados. Mas os outros signos da língua se repartiriam indiferentemente entre esses dois gêneros de textos. 
(BENVENISTE, 1966, p. 251-252).

Salientamos, desse trecho, primeiramente, que a instância utilizada pelo autor para explicar a sua proposta, é a do texto: de um lado, os diálogos orais, em que o emprego de eu é uma condição praticamente obrigatória, de outro, os tratados científicos, em que essa condição é dispensável e, às vezes, até indesejável. Mas mais importante do que meramente distinguir gêneros de textos e suas adequaçóes, Benveniste aponta, aqui, para a relação que a categoria de pessoa estabelece com o processus de enunciação linguística nos textos. Este é o ponto de capital importância para o nosso trabalho.

Processus, que lemos aqui, não é o mesmo que processo, pois não se trata apenas de sequências de açóes na realizaçáo de algo, mas trata-se do "conjunto de fenômenos, concebido como ativo e organizado no tempo", conforme definição de Robert; Rey; Rey-Debove (1987) que, parecenos, casa bem com a proposta de Benveniste (1966). Assim, acrescentase à marca de pessoa dos verbos, também o seu aspecto pessoal-temporal, lembrando que o tempo presente é sempre o tempo do eu que fala e é este tempo que pode estar implicado ou náo nos enunciados. Em conjunto ou isoladamente, essas marcas determinam a instância daquilo que é enunciado, como pertencente à realidade de quem enuncia ou, ao contrário, a uma realidade objetiva e independente da açáo ou do julgamento do locutor, do ponto de vista formal. Assim, as formas verbais estabelecem o processus textual, organizando as açôes que representam no tempo - não o tempo cronológico, mas o tempo relacionado à pessoa do discurso.

Quanto ao nível pragmático, mencionado por Benveniste no trecho da citação acima, há uma importante observação a fazer. Em Estrutura da lingua e estrutura da sociedade, o autor desenvolve essa definição, emprestada, no trecho acima, de Morris, como "tipo de linguagem que inclui aqueles que o empregam", e salienta que a inclusão do sujeito em seu discurso acrescenta "uma nova configuração da língua" em relação às configuraçóes promovidas pelas distinçóes da categoria de pessoa (entre eu e tu e entre eu/tu e ele). Isso porque a consideração pragmática da conversão da língua em discurso implica em colocar "a pessoa na sociedade como participante e que desdobra uma rede complexa de relaçóes espaço-temporais que determinam os modos de enunciação" (BENVENISTE, 1974, p. 99). A passagem de locutor a sujeito tem, então, essa amplitude, a de colocar o homem "em relação com a sociedade e com a natureza” (BENVENISTE, 1974, p. 99). É neste nível pragmático que as açóes comandadas por eu instauram-se no processus. Em 
outro nível, as ações que não incluem o tempo de $e u$, e, portanto nem a sua instância, desenvolvem-se fora do "controle" subjetivo (ainda que seja sempre eu que os apresenta como tal), num tempo e modo objetivos.

Vimos, então, que as relações das formas dos verbos do francês, demonstradas por Benveniste (1966), apontam para o tempo verbal - ressignificado pela reflexão do autor - como importante marca do estabelecimento do processus dos enunciados. $\mathrm{O}$ processus, a nosso ver, assume um papel crucial como parte da organizaçáo referencial dos enunciados, em que o locutor pode escolher, a cada enunciaçáo, a relaçáo de tempo que vai imprimir em seus enunciados, orquestrando, assim, os dois diferentes planos de enunciação: um comandado pelo tempo de $e u$, outro em que os fatos são apartados de seu tempo. $\mathrm{O}$ tempo não tem, sob esta perspectiva, a única função de indicar um evento no passado ou no futuro, portanto, mas apresenta uma propriedade textual, de indicar uma certa organização referencial-temporal e uma atitude de locução.

Com o resumo da explicação de Benveniste (1966) sobre o sistema verbal francês que fizemos na seção anterior e com essa formulação que propomos sobre o processus, já dispomos de elementos para fundamentar princípios, para um primeiro passo na investigação do funcionamento do sistema verbal do português em instaurar os dois planos enunciativos nos enunciados.

\section{A ossatura do sistema verbal no processus textual do português}

Como vimos, a questão inicial de Benveniste (1966) foi a de investigar quais formas verbais devem ser consideradas como temporais. Porém, antes de adentrar na discussão dos problemas específicos sobre o verbo francês, o autor cita alguns exemplos de textos, em que predominam ora os tempos verbais da narrativa, ora os do discurso, revelando assim essa função geral do tempo em instaurar modos enunciativos. Weinrich (1964; 1973) nos passos de Benveniste, parte, em sua reflexão, de uma análise da contagem de formas verbais em textos do alemão e do francês, relacionando a distribuição dos tempos e suas funçôes nos dois modos enunciativos, nas duas línguas. Com isso, ambos os autores inferem uma "ossatura" dos sistemas verbais do francês e do alemão, em que formas do pretérito, que não remetem ao tempo do locutor, associam-se ao plano da narrativa, e em que formas verbais que estabelecem relação com a instância temporal de quem enuncia associamse ao plano discursivo ou do comentário, conforme Weinrich (1964;1973). 
Assim, neste artigo, exploramos a seguir dois textos em português, para também inferir a ossatura do sistema verbal do português, numa primeira análise, sob esse mesmo viés.

Texto 1

$\mathrm{Na}$ segunda semana de junho, Rodrigo foi convidado para uma reunião na casa do Cel. Alvarino Amaral. Encontrou lá vários companheiros da Revoluçáo de 23, entre os quais o Juquinha Macedo, com três de seus irmãos, e mais Chiru e Liroca. Fecharam-se na sala de visitas do palacete, mobiliada com um mau gosto pomposo: poltronas forradas de veludo, cortinas de seda, uma coluna de alabastro a um canto, sustentando um vaso horrendo. Pendia da parede, numa pesada moldura cor de ouro velho, um retrato a óleo de D. Emerenciana. Lá estava a falecida amiga de Rodrigo, com seus olhos empapuçados, seu buço, sua papada e seu jeito matriarcal.

A princípio comentaram o tempo. Liroca trocou com um dos Macedos um pedaço de fumo em rama. Alvarino quis saber da saúde de Flora. Depois entraram no assunto que os congregara. Foi o dono da casa quem falou. Como os amigos sabiam, as eleiçóes para intendente municipal iam realizarse 4 em breve. O Madruga tinha o seu candidato, mas estava decidido que a oposição se absteria de votar.

- O que eu acho errado - interrompeu-o Juquinha Macedo. - Sei que não temos jeito de ganhar, mas como exemplo, devíamos comparecer às urnas. (VERÍSSIMO, 2001, p. 437).

Benveniste (1966) observa, em seus exemplos de enunciação histórica, o mesmo que podemos ver neste excerto do romance de Érico Veríssimo, que se constrói basicamente entre formas verbais do pretérito: 9 no pretérito simples, 5 no imperfeito, 2 no imperfeito composto, 1 no mais que perfeito, 1 no futuro do pretérito e 3 no presente. E o efeito aqui também é o de intenção histórica, conforme apresentado por Benveniste: a permanência das formas do pretérito faz imaginar "todo o passado do mundo como uma narrativa contínua” (BENVENISTE, 1966, p. 241). Os poucos tempos presentes estão contidos na fala de um personagem, como já havia notado o autor:

Cada vez que no interior de uma narrativa histórica aparece um discurso, quando o historiador, por exemplo, reproduz as falas de um personagem, ou que ele mesmo intervém para julgar os acontecimentos relatados, passa-se a outro sistema temporal, o do discurso. É próprio da linguagem permitir essas transferências instantâneas. (BENVENISTE, 1966, p. 242) 
O mesmo acontece no exemplo de Balzac, transcrito acima, em que um emprego de forma do presente (permettent) denuncia a reflexão do autor e escapa ao plano da narrativa, conforme Benveniste (1966, p. 241).

Contudo, o tripé da relação pretérita do francês (aoristo, imperfeito e mais que perfeito) não é a mesma para o português, já que não temos o aoristo. Aparece aqui uma primeira distinção que é preciso fazer para o português ${ }^{4}$. Os pretéritos simples e composto, em português, não se opõem, como no francês o passé simple (aoristo) e o passé composé. As duas formas de pretérito em português podem estar vinculadas à presente instância de eu e, assim, constituir o plano discursivo. $\mathrm{O}$ que permite que uma porçáo de texto, como o que acabamos de apresentar (texto 1), seja identificada como pertencente ao plano histórico, parece-nos, é a total predominância dos tempos pretéritos e a completa ausência de indicaçáo de primeira pessoa. Assim, uma primeira hipótese, para o funcionamento do tempo verbal do português, na distribuição dos modos enunciativos seria a de que, para o plano histórico, não havendo em português um tempo de passado "absoluto" como o aoristo, as formas verbais em bloco único, no pretérito, podem surtir um certo efeito de contínuo no passado. A oposição com formas do presente promoveria uma alternância a ser destacada, como na fala do personagem, acima, ou na "intromissão" eventual do narrador.

Por oportuno, assinalamos um outro aspecto, que diz respeito à "obstinação" das formas temporais de pretérito no trecho de texto em análise, recorrendo a Weinrich (1964). O conceito de ostinato, sugerido pelo autor, vem do domínio musical, e denomina um procedimento de repetição persistente do ritmo, da melodia ou da harmonia de uma peça musical ${ }^{5}$. Trata-se não meramente de uma repetição, mas de um determinado padrão recorrente numa obra musical, que contribui para uma unidade ou consolidação métrica dos ritmos. Daí a analogia com a tessitura dos textos.

Para dar um exemplo bastante trivial do fenômeno, Weinrich explica que na carta de Goethe a Schiller, que é o seu exemplo inicial, em alemão, o local que aparece logo na primeira linha, seguido da data, "Weimar, 5.

${ }^{4}$ Vale mencionar que há estudos no Brasil, como os de Koch (1984; 2013), em que Benveniste e Weinrich são retomados, no que diz respeito a considerar diferentes planos enunciativos para a análise de textos. Porém, não são aprofundadas as particularidades dos sistemas verbais, para compreender como, diferentemente do francês e do alemão, os verbos do português se relacionam e funcionam, distinguindo modos enunciativos.

${ }^{5}$ Um exemplo bastante memorável de ostinato rítmico é o do Bolero de Ravel, marcado principalmente pela percussão. Também no jazz é um recurso rico, em que várias "camadas" de ostinatos se sobrepóem, com a entrada progressiva de diferentes instrumentos. 
September 1800 " não é preciso repetir, pois para esse gênero, está convencionado que a informaçáo que consta ali vale para todo o texto: isto é, a carta foi escrita pelo remetente, naquela cidade, naquela data, o que náo muda para todo o documento. A pergunta, menos trivial, que propóe Weinrich (1964), é a de como saber que outras indicaçóes de lugar e tempo são suscetíveis de reaparecer, alterando, assim essa orientação. Observando, entáo, o quanto as indicaçóes de lugar e data são pouco recorrentes (nas cartas, mas também nos textos de modo geral), se comparadas com a frequência das formas temporais dos verbos, é que Weinrich (1964) propóe a noção de "obstinação". Para este autor, as formas temporais estão entre os primeiros signos mais "obstinados", o que náo acontece por acaso:

A sucessão dos tempos num texto obedece manifestadamente a um certo princípio de ordem. Numerosas são as constelaçóes temporais, verdadeiras nuvens em que se condensam, na vizinhança imediata, as formas de um mesmo tempo. (WEINRICH, 1973, p. 20)

O autor constata que, para além da diversidade de situaçóes ou de gêneros literários há "a clara dominância de um tempo ou de um grupo de tempos. O fenômeno geral da 'obstinação' temporal é acompanhado do fenômeno menos específico da dominância temporal' (WEINRICH, 1973, p. 20). Com isso, reforçamos nossa hipótese sobre a funçáo crucial da obstinaçáo temporal do pretérito em português, formando "blocos narrativos", que pode ser decisiva para a manutenção do foco histórico, como no exemplo do texto 1 .

Selecionamos da obra de Weinrich (1964; 1973), além do ostinato, uma segunda ideia que complementa e subsidia nossa proposta de análise. Trata-se de um deslocamento que o autor faz, ao nomear o erzählte Welt, traduzido como mundo da narrativa, e o besprochene Welt, traduzido como mundo do comentário.

O primeiro diz respeito ao mundo-objeto de narrativa, e seria um desenvolvimento do que Benveniste propôs como plano histórico. Neste mundo está implicado, conforme Weinrich (1973), um convite a entender o que é dito de maneira mais "relaxada" ou distante, já que a intervenção do ouvinte não é imediatamente solicitada. No texto 1 , é bem o que observamos: um tempo no passado que é o passado da própria narrativa ("na segunda semana de junho"), uma reuniáo, personagens que dela participaram, uma descrição detalhada da sala de visitas onde foi realizado o encontro, o teor das conversas, tudo relatado sem que em nenhum momento o leitor seja 
solicitado a intervir ou avaliar. A atitude do interlocutor, assim, pode ser qualificada como "relaxada" diante do mundo que está sendo narrado.

O outro plano é do mundo-objeto de comentário, em claro paralelo ao plano discursivo, de Benveniste. No mundo comentado, o que é dito deve ser interpretado como algo a reagir mais imediatamente. Propomos a seguir análise do texto 2 , em que, a nosso ver, predomina o plano discursivo e vai ao encontro da caracterização do mundo comentado.

Texto 2

\section{A liberdade de expressáo no inquérito dos antidemocráticos}

$\mathrm{Na}$ decisão que autorizou as operaçóes do último dia 27 , que investigam a realizaçâo de atos antidemocráticos, o ministro do Supremo Tribunal Federal (STF) Alexandre de Moraes determinou que as postagens de parlamentares sobre os eventos não fossem apagadas. Hoje, a Procuradoria Geral da República (PGR) listou algumas delas, particularmente as que foram postadas pelos deputados Júnior Amaral, Daniel Silveira, Carla Zambelli e Alê Silva, e pelo senador Arolde Oliveira. Nas mensagens, alusōes ao fechamento do Congresso e do STF, intervenção militar e ao AI-5. O material, carregado de apelos autoritários e ultimatos, compóe parte da investigação em curso. Mas em que medida violaram ou não as leis brasileiras e os amplos espaços de liberdade de expressão que um Estado de Direito oferece? A questão é da máxima relevância para um país que pretende batalhar por manter-se em solo democrático.

Só para relembrar, o estopim para a abertura do inquérito dos atos antidemocráticos veio no dia 19 de abril, Dia do Exército, quando milhares de pessoas saíram às ruas para demonstrar apoio ao governo Jair Bolsonaro. Parte delas estendeu faixas pedindo intervenção militar e o retorno do AI5. Eventos análogos se repetiram no dia 3 de maio e depois disso, com manifestaçôes menores. De acordo com o vice-procurador da República, responsável pela condução das investigaçóes, as açôes miram pessoas envolvidas na "execuçâo de açôes contra a ordem constitucional e o Estado Democrático e provocaçáo das Forças Armadas ao descumprimento de sua missão constitucional”.

Ainda que as investigaçôes se baseiem em dispositivos previstos no ordenamento jurídico brasileiro, é necessário questionar se não estaríamos diante de um precedente perigoso para a própria vida política nacional, ainda que em alegada defesa da democracia e do Estado Democrático de Direito. No caso do inquérito em tela, os procuradores baseiam as investigaçóes na chamada Lei de Segurança Nacional (LSN). O dispositivo, herança do regime militar, foi constantemente criticado por vários juristas como entulho autoritário, que poderia abrir precedentes perigosos para perseguição política. Como avaliá-lo?

$\mathrm{Na}$ verdade, a formulação de muitos dos crimes ali previstos é bastante bem feita e necessária, salvaguardando importantes bens numa democracia. Há, 
porém, o aspecto simbólico da lei, o que é especialmente relevante quando estamos no campo da liberdade de expressáo. E a lei incrimina certas condutas nesse terreno. De fato, o art. 22 da lei estabelece como crime: "Fazer, em público, propaganda: I - de processos violentos ou ilegais para alteração da ordem política ou social; II - de discriminação racial, de luta pela violência entre as classes sociais, de perseguição religiosa; III - de guerra; IV - de qualquer dos crimes previstos nesta Lei.”

A liberdade de expressão não é absoluta, afirma sempre a melhor doutrina em todos os países civilizados e toda a tradição da nossa jurisprudência. Há inúmeros bens jurídicos, isto é, valores relevantes, previstos na Constituição, que podem justificar uma por assim dizer compressáo da liberdade de expressão numa democracia. Entram aí bens como a honra, a privacidade, a igual dignidade de todos os homens (proibição do racismo), o respeito à lei penal (proibição da incitação à prática de crimes), etc. Isso é assim em boa parte dos países livres. Requer-se sempre uma específica e pontual previsão legal.

Sáo poucas, no entanto, as democracias que pró́bem diretamente, de forma especial e específica, as expressôes contra a segurança nacional. Nesse sentido, causa certo espanto a facilidade com que o referido art. 22 da LSN vem sendo brandido por importantes vozes da sociedade brasileira. De qualquer forma, não é que propriamente a existência dessa previsão legal afronte a democracia, mas sim que tem o potencial de fazê-lo e o mínimo que se requer é uma especial cautela quando se torna necessário recorrer a esse dispositivo. De que cautela estamos falando?

Antes de tudo, a cautela de uma precisa e adequada interpretaçáo de seus dispositivos, em particular do já citado art. 22, ajuda especialmente a entender o que ele náo pró́be. Cidadãos estão perfeitamente autorizados no ordenamento jurídico brasileiro a protestar contra decisōes do STF, a criticar seus ministros, mesmo com palavras severas, como, por exemplo, a de considerá-los um estorvo para a democracia ou a de compará-los a um vírus; podem igualmente defender o impeachment desses mesmos ministros ou a mudança do critério de nomeação deles; podem ainda batalhar pela realização de uma nova Assembleia Constituinte. Nada disso é ilícito. Até mesmo é lícita a absurda interpretação do art. 142 da Constituição como conferindo às forças armadas um poder de ser o árbitro final em crises institucionais pode ser defendida. Como diz a própria LSN, em seu art. 22, $\$ 3^{\circ}$, "Não constitui propaganda criminosa a exposição, a crítica ou o debate de quaisquer doutrinas". Esse texto, aliás, vai na esteira de toda a tradição democrática brasileira que não considera criminosa a mera exposição de ideia, salvo pouquíssimos casos (como os de preconceito racial), ou a discussão sobre a oportunidade ou não de uma lei e/ou de sua mudança (a manifestação pela legalização da maconha, por exemplo, é lícita, mas não a apologia ou incitação ao uso dela).

No caso das mensagens de parlamentares que vieram a público nestes dias, é difícil ver na maioria delas algo que vá além de opinióes bastante criticáveis do ponto de vista político e moral, mas de forma alguma criminosas. Considerando ainda a imunidade material ou substantiva dos parlamentares, 
é surpreendente que algumas dessas mensagens tenham sido apresentadas na mídia como violadoras da LSN. Assim, por exemplo, a afirmação do senador Arolde de Oliveira em redes sociais de que "Os governadores do Rio e de São Paulo se elegeram nas costas de Jair Bolsonaro e agora são seus maiores detratores e inimigos do Brasil. Querem o caos, mas, antes que isso ocorra, as Forças Armadas entrarão em cena para Garantia da Lei e da Ordem, segundo a Constituição Federal" não parece representar nada mais do que uma convicção, ainda que mal fundada. Mesmo a mensagem "AI-5 e intervenção militar é o grito de desespero de um povo que quer ver o seu presidente, eleito democraticamente, governar sem as amarras de dois congressistas", de Alê Silva, em 19 de abril, não caracteriza propaganda ou incitação. É antes uma explicação de por que o povo, na visão dele, defende o AI-5 e a intervenção militar. Pouco importa quão absurdas consideremos essas análises ou mensagens; o que não se pode é pender para uma caça às bruxas em momentos de polarização política.

Há expressôes que, sim, são abusivas. Mas não é difícil identificá-las. A injúria, pura e simples (xingamentos aos ministros), a incitação à derrubada do STF ou ao golpe militar, etc... Surpreende, portanto, que manifestaçóes de parlamentares, que não se encaixam neste quadrante, sendo totalmente legais, ainda que reprováveis moral ou politicamente, estejam sendo alvo de inquérito. (Gazeta do Povo, 23/junho/2020)

Neste editorial de jornal on line, há 63 ocorrências de formas verbais no presente do indicativo, 3 no presente do subjuntivo, 2 no futuro do pretérito, 12 no pretérito simples, 1 no pretérito perfeito composto e 1 no pretérito imperfeito do subjuntivo, perfazendo um total de 82 formas verbais. O ostinato, aqui, mostra uma predominância de verbos no presente, o que condiz com o plano do discurso, de Benveniste. Somados aos verbos no presente do indicativo, pertencem ao plano do discurso também os do presente do subjuntivo e os do futuro do pretérito, como podemos verificar no texto. O locutor, responsável pelo editorial, convoca seus leitores para o debate, e, ao mesmo tempo, revela seu ponto e vista, como comprovam as formas verbais "é necessário se questionar se não estaríamos diante de um precedente perigoso", "pouco importa o quão absurdas consideremos" e "como avaliá-lo?", em forma de pergunta direta. É bem o mundo do comentário que se configura aqui.

Os verbos nas formas pretéritas, em número bem menor, caracterizam o mundo narrado e são empregados, nesse editorial, para munir de "fatos" o locutor, o qual pode, assim, seguir seu posicionamento sobre a questáo. Da maneira como aparecem no editorial, o passado dessas açôes não é um passado "particular" do locutor, mas um passado cronológico de notícias de acontecimentos políticos, comum a todos os brasileiros. Isso pode ser visto 
como estratégia argumentativa, trazendo essas informaçóes-fatos, as quais se revestem de um caráter da ordem do incontestável, pelo modo como são apresentadas. Por exemplo, as afirmaçóes, todas em $3^{\text {a }}$. pessoa, no pretérito "o ministro... determinou", "a Procuradoria... listou", "parte delas estendeu faixas”, etc. são dadas como fatos. A partir deles é que são emitidas então as opiniôes e juízos de valor do locutor: "é difícil ver", "pouco importa quão absurdas consideremos", "surpreende...que manifestaçôes sejam alvo de inquérito", etc. Ressaltamos sobretudo, nessa estratégia, o recurso da passagem de um modo enunciativo a outro, que permite produzir esse efeito entre fatos históricos e comentários e organiza o processus do texto.

Por fim, ainda com o texto 2 sob análise, confirmamos que as noçóes de mundo-objeto da narrativa e mundo-objeto do comentário evidenciam a ideia de que as formas verbais manifestam atitudes do locutor diante do mundo, ora narrando o mundo, ora comentando o mundo. Sáo diferentes modos de enunciar que se apresentam ao falante e em que o tempo verbal se impóe como uma categoria essencial em jogo.

\section{Consideraçóes finais}

Inspirados pela proposta de Benveniste (1966), alertamos para o fato de que um estudo sistemático das diversas formas verbais do português e seu emprego precisa ser realizado para que se chegue a um panorama mais amplo das suas atuaçóes nos dois planos de enunciação. Nossa proposta para este artigo foi o de realizar uma pequena parte disso. Apresentamos uma análise de dois textos, para observar, numa primeira aproximação, como se comportam os verbos no português, na distinção dos dois diferentes modos enunciativos. Nos dois textos analisados, os verbos no pretérito compuseram o plano histórico, ou mundo narrado, ao passo que o presente marcou o plano discursivo, ou mundo comentado - tendência observada também nas línguas estudadas pelos autores de referência, quais sejam, o francês e o alemão.

Além da importância da adequaçáo ao tom que se quer dar aos enunciados, esse recurso pode desempenhar um forte papel argumentativo, na medida em que o falante pode regular, através das formas temporais dos verbos, a sua inserçáa sobre o que é dito, ora narrando eventos, apresentados como tendo sido produzidos à revelia do seu próprio ponto de vista sobre a questão, ora se engajando e envolvendo o interlocutor.

Finalmente, concluímos, observando que a organização temporal- 
pessoal dos eventos enunciados é crucial para a organização textual e para a intercompreensão entre os falantes, pois é nesse processus também que os falantes podem inferir de que maneira os textos devem ser interpretados.

Sugerimos, então, que o tempo verbal possa integrar os estudos linguísticos como uma categoria de análise textual, em que se observe a distribuição das formas em ostinato e as alternâncias, que marcam a permanência ou a mudança de modo enunciativo, respectivamente.

\section{Referências bibliográficas}

BENVENISTE, Émile. Problèmes de linguistique générale, I. Paris: Éditions Gallimard, 1966.

$$
1974 .
$$

. Problèmes de linguistique générale, II. Paris: Éditions Gallimard,

CIULLA, Alena. A distinção de pessoa e alguns aspectos da contribuição de Benveniste para o estudo da enunciação. In: CAVALCANTE, Sávio André et al. (Orgs.). Linguística: os conceitos que todos precisam conhecer São Paulo: Pimenta Cultural, 2020a. (no prelo).

CIULLA, Alena. A referência e a dêixis em Benveniste. In: FERNANDES, Giovane Oliveira; ARESI, Fábio. (Orgs.). O universo benvenisteano: enunciação, sociedade e semiologia. São Paulo: Pimenta Cultural, 2020b. (no prelo).

KOCH, Ingedore Villaça. Argumentação e linguagem. São Paulo: Cortez, 1984.

$\mathrm{KOCH}$, Ingedore Villaça. A inter-ação pela linguagem. São Paulo: Contexto, 2013.

GAZETA DO POVO. Editorial: A liberdade de expressão no inquérito dos atos antidemocráticos. Publicado em 23/06/2020. Disponível em: Leia mais em: https:/www.gazetadopovo.com.br/opiniao/editoriais/aliberdade-de-expressao-no-inquerito-dos-atos-antidemocraticos/. Acesso em: 30 jun. 2020.

HOFF, Sara Luiza. A nota "La traduction, la langue et l'intelligence": o fenômeno tradutório na e a partir da reflexão sobre a linguagem de Benveniste. 204f. 2018. Dissertação (Mestrado em Linguística) - Instituto de Letras, Universidade Federal do Rio Grande do Sul, Porto Alegre, 2018. Latraduction dumondenouveau.Sincère? Por monepeelabible, Centerblog. 
net, 8/5/2008. Seção: Qu'enseigne réellement la Bible, Études approfondis. Disponível em : http://monepeelabible.centerblog.net/4860500-La\%E2\%80\%9CTraduction-du-monde-nouveau $\%$ E2\%80\%9D-Sincere-. Acesso em : 19 jun. 2020.

ROBERT, Paul; REY, Alain; REY-DEBOVE, Josette. Le Petit Robert. Paris: Dictionnaires Le Robert, 1988.

VERÍSSIMO, Érico. O tempo e o vento. O arquipélago 2. Porto Alegre: Globo, 2001.

WEINRICH, Harald. Tempus. Besprochene und erzählte Welt. Sttutgart: W. Kohlhammer GmbH,1964.

WEINRICH, Harald. Le temps: le récit et le commentaire. Paris : Éditions du Seuil, 1973. 